\title{
Establishment of a Versatile Seminoma Model Indicates Cellular Plasticity of Germ Cell Tumor Cells
}

\author{
Daniel Nettersheim, ${ }^{\dagger \dagger}$ Birgit Westernströer, ${ }^{2 \dagger}$ Natalie Haas, ${ }^{1}$ Anke Leinhaas, ${ }^{3}$ Oliver Brüstle, ${ }^{3}$ Stefan Schlatt, ${ }^{2}$ \\ and Hubert Schorle ${ }^{1 *}$ \\ 'Department of Developmental Pathology, Institute of Pathology, University of Bonn, Medical School, Bonn, Germany \\ ${ }^{2}$ Center for Reproduction and Andrology CeRA, University of Münster, Medical School, Münster, Germany \\ ${ }^{3}$ Institute for Reconstructive Neurobiology, Life and Brain Center, University of Bonn, Medical School, Bonn, Germany
}

In western countries, $60 \%$ of all malignancies diagnosed in men between 17-45 years of age are germ cell tumors (GCT). GCT arise from the common precursor lesion carcinoma in situ, which transforms within an average of 9 years into invasive Type-II GCTs. Seminomas are considered to be the default developmental pathway of carcinoma in situ cells and the seminoma-like cell line TCam-2 has been used to study seminoma biology in vitro. However, the generation of an animal model, which would allow for the in vivo analysis of seminoma formation, remained elusive. We applied transplantation approaches using TCam-2 cell transfer into ectopic (skin, brain) and orthopic (testis) sites of immunodeficient mice. We demonstrate that a transplantation into the seminiferous tubules results in formation of a carcinoma in situ/seminoma. In contrast, TCam-2 cells adopt an embryonal carcinoma-like fate when grafted to the flank or corpus striatum and display downregulation of the seminoma marker SOXI7 and upregulation of the embryonal carcinoma markers SOX2 and CD30. Grafted TCam-2 cells reduce AKT-, ERK-, EphA3-, and Tie2/TEK-signaling to levels comparable to embryonal carcinoma cells. Hence, TCam-2 cell transplantation into the testis generated a carcinoma in situ/seminoma mouse model, which enables addressing the biology of these tumors in vivo. The fact that TCam-2 cells give rise to a carcinoma in situ/seminoma or embryonal carcinoma in a transplantation site specific manner implies that conversion of carcinoma in situ/seminoma to an embryonal carcinoma does not require additional genetic aberrations but relies on signals from the tumor-microenvironment. (c) 2012 Wiley Periodicals, Inc.

\section{INTRODUCTION}

Germ cell tumors (GCTs) are the most common cancer type in young men with increasing incidence in western countries (Adami et al., 1994). GCTs arise from carcinoma in situ (CIS) cells, which are thought to originate from a gonocyte blocked in maturation (Sonne et al., 2009). This precursor lesion transforms within an average of 9 years into an invasive GCT (Jorgensen et al., 1990). These tumor entities were classified into different groups (Oosterhuis and Looijenga, 2005). Teratomas and yolk-sac tumors of infants and young adults belong to Type I, while seminomas and nonseminomas are Type II GCTs. Seminomas and embryonal carcinomas (EG) represent the most frequent subtypes of Type II GCTs. While seminomas are considered the default developmental pathway of CIS cells (de Jong et al., 2008,b) and resemble undifferentiated germ cells, ECs are pluripotent and eventually differentiate into teratomas, choriocarcinomas and yolk-sac tumors. The tumor biology of ECs can be recapitulated and analyzed in vitro by taking advantage of several human EC cell lines and in vivo by EC-xenografts in mice (Bronson et al.,
1980; Damjanov et al., 1993; Damjanov, 2004; Josephson et al., 2007). However, the molecular pathways involved in seminoma formation remain elusive. While the well characterized human seminoma-like cell line TCam-2 (de Jong et al., 2008a; Eckert et al., 2008a,b) allows for studying seminoma biology in vitro, to date, no animal model is available to analyze seminoma formation and progression in vivo.

Here, we demonstrate that transfer of TCam-2 cells into the seminiferous tubules of mice resulted in formation of a CIS/seminoma, while transplantation into the trunk (flank) or central nervous system

\footnotetext{
Additional Supporting Information may be found in the online version of this article.

${ }^{\dagger}$ These authors contributed equally to this work.

Supported by: DFG, Grant number: Scho-503/9; Deutsche Krebshilfe, Grant number: 108249; Kompetenznetzwerk Stammzellforschung NRW.

*Correspondence to: Hubert Schorle, Department of Developmental Pathology, Institute of Pathology, Sigmund-Freud-Strasse 25, 53127 Bonn, Germany. E-mail: hubert.schorle@ukb.uni-bonn. de

Received 23 January 2012; Accepted 2 March 2012

DOI 10.1002/gcc.21958

Published online in

Wiley Online Library (wileyonlinelibrary.com).
} 
TABLE I. Oligonucleotides Used in RT-PCR Experiments

\begin{tabular}{|c|c|c|c|c|}
\hline Marker gene & Forward primer $5^{\prime}-3^{\prime}$ & Reverse primer $5^{\prime}-3^{\prime}$ & $\operatorname{Tan}\left({ }^{\circ} \mathrm{C}\right)$ & Cycles \\
\hline AFP & AGCTTGGTGGTGGATGAAAC & CССТCTTCAGCAAAGCAGAC & 60 & 30 \\
\hline TFAP2C & CCCACTGAGGTCTTCTGCTC & AGAGTCAC ATGAGCGGCTTT & 60 & 25 \\
\hline BLIMPI & GGGTGCAGCCTTTATGAGTC & CCTTGTTCATGCCCTGAGAT & 60 & 30 \\
\hline BRACHYURY & GGGTGGCTTCTTCCTGGAAC & TTGGAGAATTGTTCCGATGAG & 60 & 35 \\
\hline CD30 & AGCTAGAGCTTGTGGATTCCAG & GTCTTCTTTСССТTССТСТTCС & 58 & 30 \\
\hline cKIT & TCATGGTCGGATCACAAAGA & AGGGGCTGCTTCCTAAAGAG & 60 & 25 \\
\hline GAPDH & TGGTATCGTGGAAGGACTCATG AC & ATGCCAGTGAGCTTCCCGTTCAGC & 60 & 22 \\
\hline GDF3 & AGACTTATGCTACGTAAAGGAGCT & CTTTGATGGCAGACAGGTTAAAGTA & 60 & 30 \\
\hline HANDI & ACATCGCCTACCTGATGGAC & CGGCTCACTGGTTTAACTCC & 60 & 30 \\
\hline MCFD2 & CCCTGTGGCTTTGTAGGGTA & GCAGAAGGGAAATGTGGTGT & 60 & 30 \\
\hline NANOG & GATTTGTGGGCCTGAAGAAA & AAGTGGGTTGTTTGCCTTTG & 58 & 25 \\
\hline ОСТ3/4 & CGAAAGAGAAAGCGAACCAG & GCCGGT TACAGAACCACACT & 60 & 22 \\
\hline PAX6 & ACCCATTATCCAGATGTGTTTGCCCGAG & CTGCCGCCTATGCCCAGCTTCACCAT & 60 & 30 \\
\hline SOXI7 & GAGGGCCAGAAGCAGTGTTA & AGTGATTGTGGGGAGCAAGT & 60 & 25 \\
\hline SOX2 & ATGCACCGCTACGACGTGA & CTTTTGCACСССТСССАTT & 60 & 25 \\
\hline VASA & AGAAA GTAGTGATACTCAAGGACCAA & TGA CAGAGATTAGCTTCTTC AAAAGT & 60 & 35 \\
\hline
\end{tabular}

(CNS) (corpus striatum) resulted in growth of EClike tumors-a process that is accompanied by upregulation of EC-specific genes and adaptation to EC-characteristic pathway signaling.

\section{MATERIAL AND METHODS}

\section{Cell Culture}

TCam-2 and 2102EP cells (obtained from Dr. Janet Shipley, Institute of Cancer Research, Sutton, England and Dr. Stefanie Gläsener, UKE Hamburg, Germany) were cultivated in RPMI (TCam-2) or DMEM (2102EP) medium supplemented with $10 \%$ FCS, $1 \%$ penicillin/streptomycin, $200 \mathrm{mM} \mathrm{L-glutamine} \mathrm{at} 37^{\circ} \mathrm{C}$ and $5 \% \mathrm{CO}_{2}$.

\section{RT-PCR}

RNA was extracted by TRIzol (Sigma, Taufkirchen, Germany) according to manufacturer's instructions. RNA quality and concentration was measured by NanoDrop spectrophotometer (PeqLab, Erlangen, Germany). First-strand synthesis was performed according to "RevertAid First Strand cDNA Synthesis Kit" manual (Fermentas, St. Leon-Rot, Germany). About $500 \mathrm{ng}$ of total RNA were used for each first-strand synthesis. About 1.5 $\mu \mathrm{l}(37.5 \mu \mathrm{g})$ cDNA was used for each PCR reaction. PCR was carried out at $95^{\circ} \mathrm{C}$ for $1 \mathrm{~min}$, followed by 25-35 cycles of $94^{\circ} \mathrm{C}$ for $30 \mathrm{sec}, 58-60^{\circ} \mathrm{C}$ for $30 \mathrm{sec}$ and $72^{\circ} \mathrm{C}$ for $45 \mathrm{sec}$. For primer details, see Table 1 .

\section{Immunohistochemistry}

Tumor tissues were dissected, fixed in $4 \%$ phosphate-buffered formalin for 1-2 days at room temperature and processed in paraffin wax. Dewaxed, 4- $\mu \mathrm{m}$ thick tissue sections were microwave pretreated in Citrate-buffer $(10 \mathrm{mM}$ citric acid, pH 6). Endogenous peroxidase was blocked for 5 min in $3 \%$ hydrogen peroxide (diluted in distilled water). Sections were washed with $1 \times$ PBS and unspecific binding sites were blocked with $1.5 \%$ BSA/PBS $+10 \%$ horse serum for $1 \mathrm{hr}$ at room temperature. Primary antibodies, diluted in $1.5 \%$ BSA/PBS, were applied for $2 \mathrm{hr}$ at room temperature. Thereafter, a biotin-conjugated secondary antibody was applied for $1 \mathrm{hr}$ at room temperature. The staining was visualized with 3-amino-9-ethylcarbazole (AEC Substrate-Chromogen, DAKO, Hamburg, Germany) and counterstained with haematoxylin. Negative controls were performed using blocking solution instead of the primary antibody. For antibody details see Table 2.

\section{Western Blot}

Proteins were isolated by RIPA-buffer $(50 \mathrm{mM}$ TRIS-HCl pH 8, $150 \mathrm{mM} \mathrm{NaCl,} \mathrm{1 \%} \mathrm{NP-40,}$ $0.5 \%$ sodium deoxycholate, $0.1 \%$ SDS +1 tablet of protease inhibitor cocktail (Roche, Mannheim, Germany)). The lysates were incubated for 30 min at $4^{\circ} \mathrm{C}$, followed by a 20 -min centrifugation step at $12.000 \mathrm{~g}$ at $4^{\circ} \mathrm{C}$. The supernatant was used for western blot analysis. The protein concentrations were determined by BCA Protein Assay Kit (Pierce, Rockford, IL). For protein analysis, we used the Mini-PROTEAN Electrophoresis Cell and Mini Trans-Blot system (BioRad, Munich, Germany). SDS-PAGE was carried out at $90 \mathrm{~V}$ for approximately $90 \mathrm{~min}$. Gels were blotted onto a polyvinylidene fluoride membrane 
TABLE 2. Primary and Secondary Antibodies Used for Immunohistochemistry and Western Blotting

\begin{tabular}{|c|c|c|c|c|c|}
\hline & Clone/order code & Company & Source & IHC dilution & WB diluton \\
\hline \multicolumn{6}{|l|}{ Primary antibody } \\
\hline AFP & $\mathrm{A} 0008$ & Dako & Rabbit & $\mathrm{I}: 200$ & \\
\hline Beta-actin & AC-74 & Sigma Aldrich & Mouse & - & $\mid: 20,000$ \\
\hline BLIMPI & - & - & Rabbit & $\mathrm{I}: 200$ & \\
\hline CD30 & Ber-H2/M076I & Dako & Mouse & $\mathrm{I}: 200$ & \\
\hline cKIT & A4502 & Dako & Rabbit & $1: 200$ & \\
\hline $\mathrm{hCG}(\beta)$ & AHP536 & Serotec & Rabbit & $\mathrm{I}: 300$ & \\
\hline MAGEA4 & $57 B$ & - & Mouse & $\mathrm{I}: 200$ & \\
\hline OСТ3/4 & C- 10 & Santa Cruz & Mouse & $\mathrm{I}: 200$ & \\
\hline pERKI/2 & 9101 & Cell Signaling & Rabbit & - & $1: 1,000$ \\
\hline PGP9.5 & $\mathrm{Z} 5116$ & Dako & Rabbit & $\mathrm{I}: 300$ & \\
\hline PRMT5 & AB3349 & Chemicon & Rabbit & $\mathrm{I}: 200$ & \\
\hline SOX17 & GTI5094 & Neuromics & Goat & $1: 50$ & \\
\hline sox2 & AF2018 & R\&D systems & Goat & $\mathrm{I}: 100$ & \\
\hline VASA & abl 3840 & Abcam & Rabbit & $\mathrm{I}: 200$ & \\
\hline \multicolumn{6}{|c|}{ Secondary antibody } \\
\hline Anti-goat HRP & $61-1620$ & Invitrogen & Rabbit & $\mathrm{I}: 400$ & \\
\hline Anti-mouse HRP & $61-0120$ & Invitrogen & Rabbit & $\mathrm{I}: 400$ & \\
\hline Anti-rabbit HRP & $65-6120$ & Invitrogen & Goat & $1: 400$ & \\
\hline Anti-rabbit HRP & sc2955 & Santa cruz & Chicken & $1: 100$ & \\
\hline Anti-goat HRP & sc296I & Santa cruz & Chicken & $\mathrm{I}: 100$ & \\
\hline
\end{tabular}

in a BioRad blotting chamber overnight at $30 \mathrm{~V}$ at $4^{\circ} \mathrm{C}$. After the membrane had been blocked in $5 \%$ low fat dry milk powder (LFDMP)/PBS for at least $1 \mathrm{hr}$ at room temperature, primary antibodies, diluted in 5\% LFDMP/PBS, were applied for $3 \mathrm{hr}$ at room temperature, followed by HRPconjugated secondary antibodies for $1 \mathrm{hr}$. Finally, the membrane was incubated in $1 \mathrm{ml}$ PierceSuper Signal West Pico chemiluminescent substrate (Perbio, Bonn, Germany) for $5 \mathrm{~min}$ and the signal was detected by using Kodak X-Ray film (SigmaAldrich, Taufkirchen, Germany). For antibody details, see Table 2.

\section{Gene Expression Profiling by Affymetrix Array}

TCam-2 cells were analyzed using the Affymetrix GeneChip Human Genome U133A plus 2.0 array. The sample preparation, Affymetrix array, data normalization, data analysis and visualisation were perfmored as described in depth by Looijenga et al. (2006). Ten micrograms of total RNA were used to prepare anti-sense biotinylated RNA, according to the Affymetrix GeneChip eukaryotic one-cycle target preparation protocol (Affymetrix, Santa Clara, CA).

\section{Injection of TCam-2/2 I 202EP Cells into the Flank}

TCam-2 and 2102EP cells were cultivated for 8 days in standard growth medium. Cells were trypsinized, counted and $1 \times 10^{7}$ cells were resuspended in $500 \mu \mathrm{l}$ of $4^{\circ} \mathrm{C}$ cold Matrigel (BD,
Heidelberg, Germany) and injected into the flank of CD1 nude mice using a cold $27 \mathrm{G}$ syringe (BD, Heidelberg, Germany).

\section{Injection of TCam-2/2I 02EP Cells into the Seminiferous Tubules}

Five weeks before TCam-2/2102EP injection, busulfan (40 mg/kg) was injected intraperitoneally into male NRMI-Foxn ${ }^{\text {nu }} /$ Foxn $^{\text {nu }}$ mice. At the day of injection, TCam-2/2102EP cells were trypsinized and counted. About $1 \times 10^{5}$ cells were resuspended in $10 \mu \mathrm{l}$ standard growth medium plus $0.05 \%$ trypan-blue to monitor the injection process. About $10 \mu \mathrm{l}$ of the cell suspension were injected under pressure (100-400 hPa, FemtoJet, Eppendorf, Hamburg, Germany) into the seminiferous tubule via the efferent duct.

\section{Injection of TCam-2/2102EP Cells into the Corpus Striatum}

At the day of injection, TCam-2/2102EP cells were trypsinized and counted. Per injection $1 \times$ $10^{5}$ cells were resuspended in $2 \mu \mathrm{l}$ PBS. CD1 nude ice was anaestesized by ketamin-xylazine into the peritoneum and fixed afterwards in the injection apparatus. After the cranial bone was laid open, a small hole was drilled into the cranial bone at the injection site. Cells were injected through this hole into the corpus striatum via a syringe. 


\section{PathScan Signaling Array}

The PathScan Signaling Array (Cell Signaling Technology, Frankfurt, Germany) was performed according to the manufacturers recommendations. About $150 \mu \mathrm{g}$ total protein extract was used per assay and samples were run in duplicates. The chemiluminescent signals were detected using Kodak BioMax light films (Sigma Aldrich, Steinheim, Germany). Pixel intensities were quantified by ImageJ-software (http://rsbweb.nih.gov/ij/) and normalized to individual background intensities.

\section{Statistical Analysis}

Standard deviations were calculated after normalization of the PathScan Signaling Array data set to the background noise and after weighting the testes and seminal vesicles 1 and 3 months after transplantation. A Student's $t$-test was performed to determine the significance of the measured differences in testes and seminal vesicle weight. Significance level $\alpha=5 \%$.

\section{RESULTS}

The seminoma derived cell line TCam-2 cells display a seminoma-like character in vitro and can be induced to convert into a mixed nonseminoma by defined conditions (Eckert et al., 2008a,b; Nettersheim et al., 2011). These results suggested that seminomas might be instructed by signals from the tumor-microenvironment to convert to nonseminoma (i.e. embryonal carcinoma) without the requirement of an additional mutation. Unfortunately, there is no in vivo seminoma model available to test this hypothesis. In order to further extend these findings to the in vivo situation, we decided to transplant cell lines representing seminoma (TCam-2) and nonseminoma (2102EP) to different sites in mice.

In humans, CIS-cells reside as small nests within the seminiferous tubules of the testes (intratubular neoplasia). Also, seminomas and ECs initially grow within these tubules. Hence, we decided to perform a heterologous transfer of human GCT cells into the seminiferous tubules of busulfan-treated immunodeficient mice. Histological analysis of the testes 1 month after transplantation revealed that the TCam-2 cells had formed clusters of large, round cells with clear cytoplasm and big, round nuclei (Fig. 1A, red arrow). These are morphological hallmarks of CIS/seminoma formation (HoeiHansen et al., 2005). Three months after transplantation, the CIS-like nests persisted, but parts

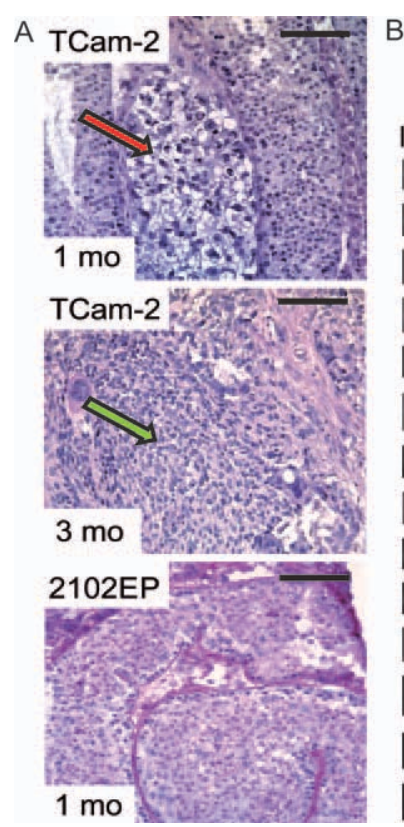

\section{B}

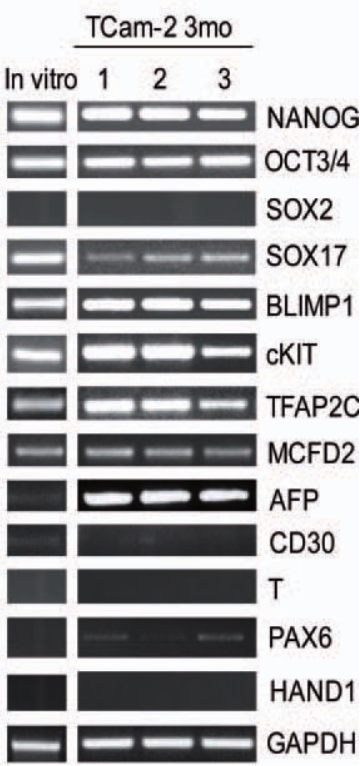

Figure I. (A) HE or PAS staining of testis sections I and 3 months after injection of TCam-2 (HE) and 2IO2EP cells (PAS) into the seminiferous tubules. Red arrows point at CIS-like cells, while the green arrow points at more differentiated appearing cells. Scale bars: 100 $\mu \mathrm{m}$. (B) RT-PCR of indicated markers of in vitro cultivated TCam-2 and testis tissues 3 months after transplantation of TCam-2 (TCam-2, 3 months). GAPDH was used as endogenous control. [Color figure can be viewed in the online issue, which is available at wileyonlinelibrary.com.]

of the transplant presented as small, round to polygonal and eosinophilic cells indicating progression of the CIS cells to the invasive GCT entities (Fig. 1A, green arrow). The testis-transferred 2102EP cells grew as an EC from the beginning (Fig. 1A, 2102EP).

To validate the CIS/seminoma-like nature of the lesions, we performed RT-PCR and demonstrated expression of the CIS/seminoma markers NANOG, OCT3/4, KIT, BLIMP1, TFAP2C, $M C F D 2$, and $S O X 17$ (Fig. 1B). The lesions were negative for EC markers $(S O X 2, C D 30)$ as well as mesoderm markers (BRACHYURY (T), HAND1) but expressed the markers for endoderm $(A F P)$ and ectoderm $(P A X 6)$. IHC analyses further verified expression of OCT3/4, KIT, SOX17, and AFP (Figs. 2A-2H). Of note, expression of AFP was confined to cells having lost the CIS-like morphology. Like the parental TCam-2 cells in vitro, the grafted cells remained negative for MAGEA4 and displayed only focal $\beta$-hCG staining. Furthermore, expression of the late germ cell marker VASA or the spermatogonia marker PGP9.5 was not detected (Figs. 2I-2P), indicating that the grafted TCam-2 cells did not initiate germ cell differentiation. The results suggested that intratesticular transplantation of the 

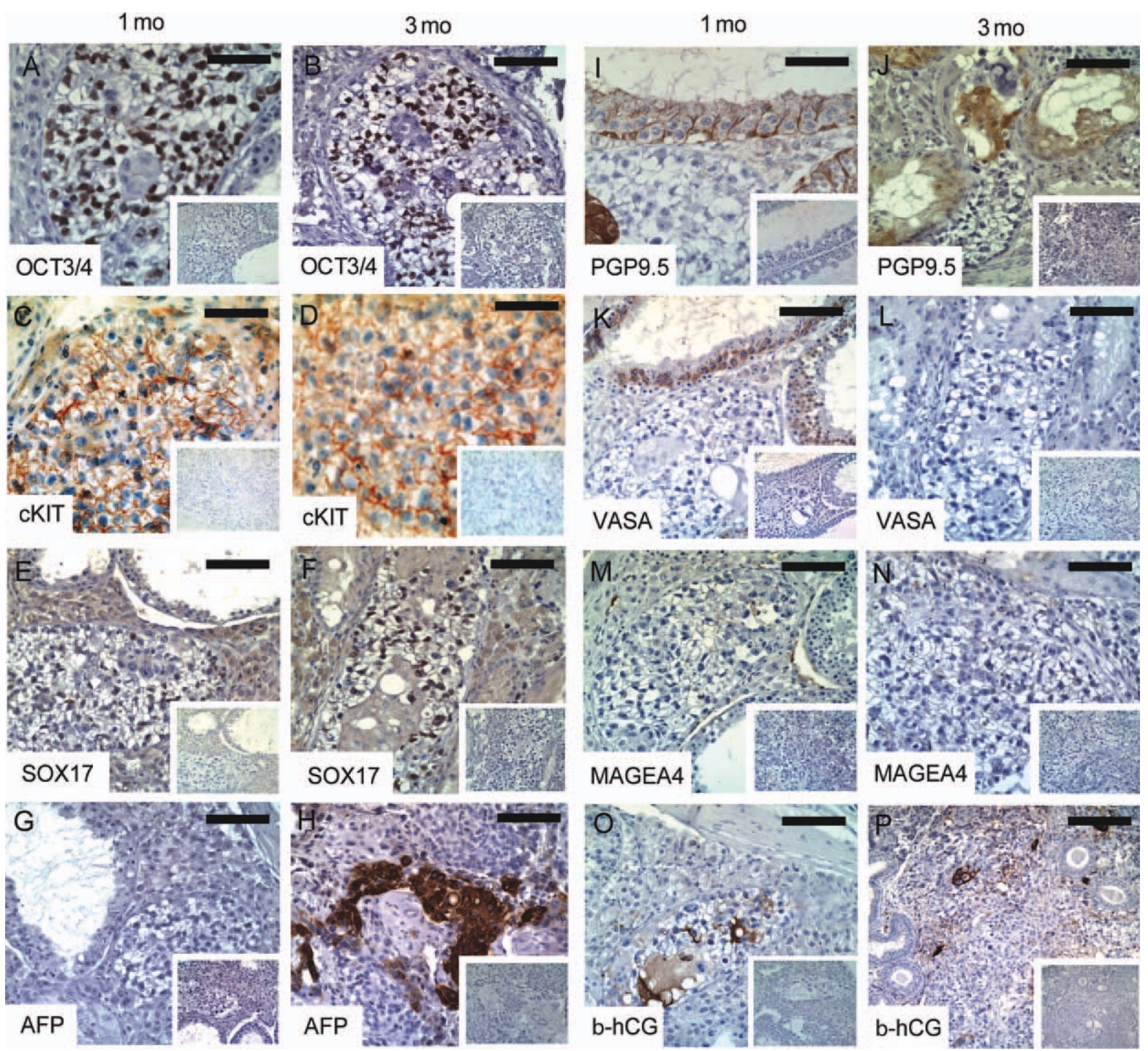

Figure 2. IHC staining of indicated markers I and 3 months after TCam-2 injection into the seminiferous tubules of nude mice. Secondary antibody controls are given in the lower, right corners. Scale bars: A-B, E-F, K-P, $200 \mu \mathrm{m} ; \mathrm{C}-\mathrm{D}, \mathrm{I}-\mathrm{J}, 100 \mu \mathrm{m}$. [Color figure can be viewed in the online issue, which is available at wileyonlinelibrary.com.]

seminoma-like cell line TCam-2 results in initiation of a CIS/seminoma based on morphology, gene expression, and cellular localization of the proteins.

Of note, the left and right testis weights did not differ strongly 1 and 3 months after TCam-2 injection (Supporting Information Fig. 1A) and derived tumors remained within the testis. Transplantation of 2102EP cells resulted in a significant increase of the left testis weight (Supporting Information Fig. 1A) and huge tumor masses could be found that had already penetrated the confines of the testes (Supporting Information Fig. 1B). Furthermore, the seminal vesicles of the TCam-2injected mice were significantly heavier compared to those of 2102EP-injected mice (mean 529/521 vs. $320 \mathrm{mg}$; $P$-value TCam-2, 1 month vs. 2102EP: 0.013; $P$-value TCam-2, 3 months vs. 2102EP: 0.014 (Supporting Information Fig. 1C).

Mizuno et al. (1993) have reported that TCam2 cells present as EC-like tumors when transplanted into the flank of mice. We hypothesized that, in order to convert from seminoma to EC, TCam-2 cells must downregulate the seminoma marker SOX17 and upregulate the EC markers SOX2 and CD30. Therefore, TCam-2 cells were transplanted into the flank of nude mice and tumors ( $n=3$ for each time point) were analyzed for expression of SOX2, SOX17, and CD30 by RT-PCR and/or IHC. Up to 2 weeks after 

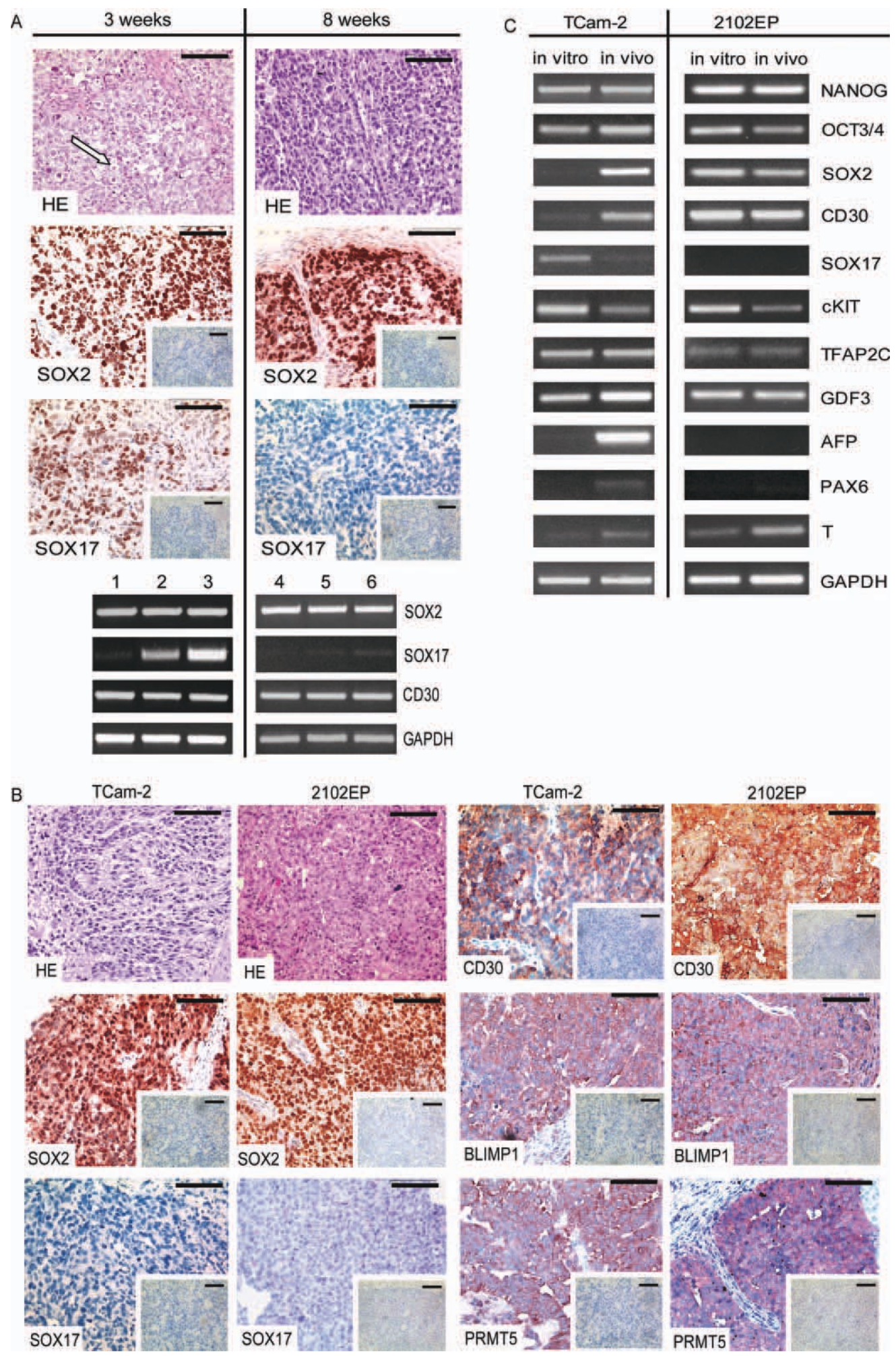

Figure 3. (A) HE and IHC staining of SOX2 or SOXI7 3 and 8 weeks after TCam-2 injection into the murine flank as well as RTPCR of indicated markers $3(\mathrm{I}-3)$ and 8 weeks (4-6) after transplantation. The white arrow points at a CIS/seminoma-like cell. Secondary antibody controls are given in the lower, right corners. Scale bars: $100 \mu \mathrm{m}$. (B) HE and IHC staining of indicated markers in tumor tissues 8 weeks after TCam-2 flank injection. 2102EP cells served as

control. Secondary antibody controls are given in the right, lower corners. Scale bars: $100 \mu \mathrm{m}$. (C) RT-PCR of indicated markers of in vitro cultivated and 8 weeks in vivo grown TCam-2/2/20EP cells. GAPDH was used as endogenous control. [Color figure can be viewed in the online issue, which is available at wileyonlinelibrary.com.] 

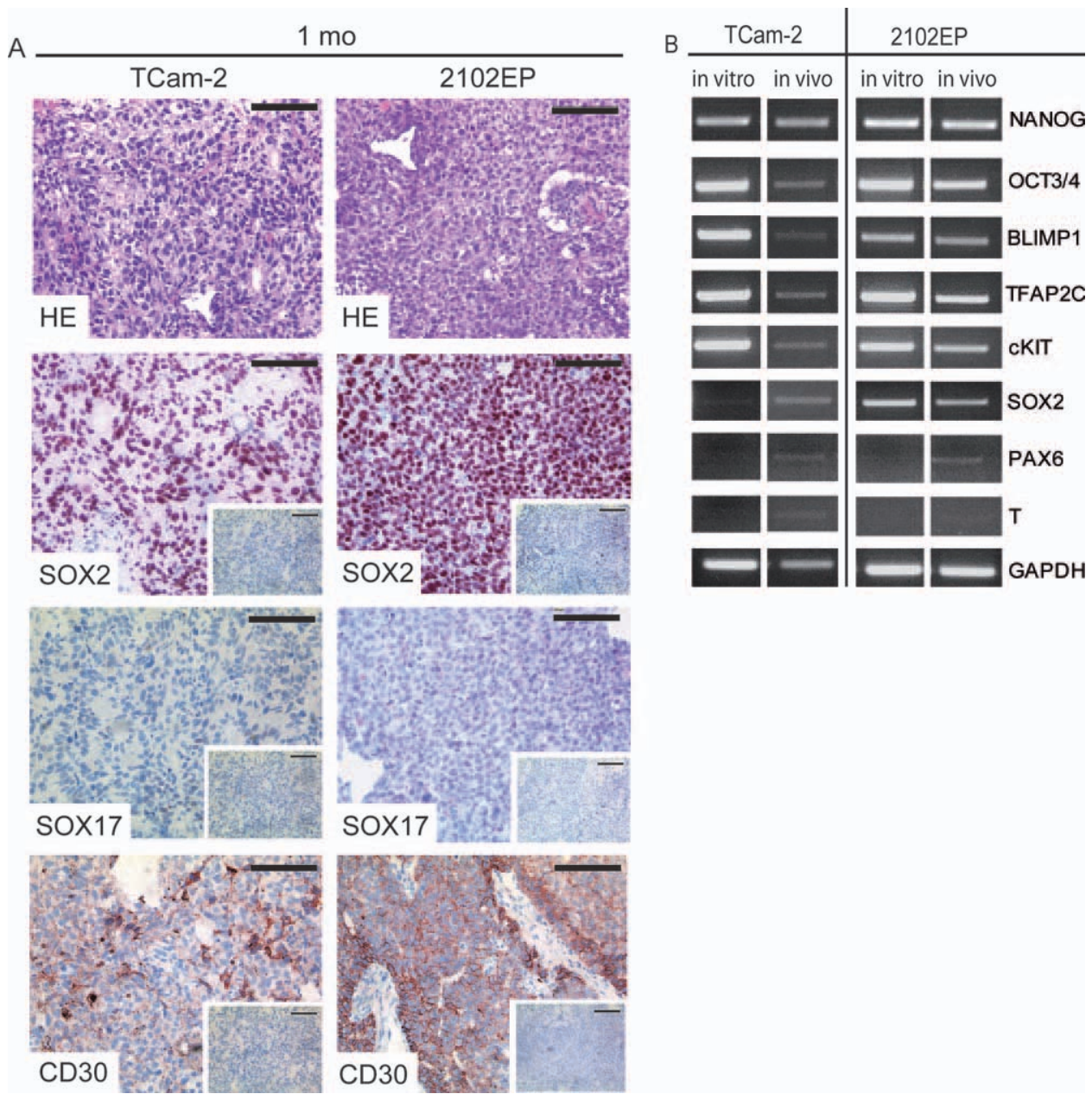

Figure 4. (A) $\mathrm{HE}$ and $\mathrm{IHC}$ staining of indicated markers in TCam2 and 2102EP cells I month after injection into the corpus striatum of nude mice. Secondary antibody controls are given in the lower, right corners. Scale bars: $100 \mu \mathrm{m}$. (B) RT-PCR of indicated markers of in vitro cultivated and in vivo grown TCam-2/2I20EP cells 4 weeks after injection into the corpus striatum of nude mice. GAPDH was used as endogenous control. [Color figure can be viewed in the online issue, which is available at wileyonlinelibrary.com.] transplantation, the tumors displayed the typical seminoma-like morphology (Supporting Information Figs. 2A and 2B). After 3 weeks, cells with a seminoma-like morphology were still detectable; however, many of cells presented with an EClike morphology (Fig. 3A, white arrow) and by 8 weeks, all cells of the tumor had adopted the EC-like morphology. On the molecular level, during the first 2 weeks the majority of cells remained positive for SOX17 (Supporting Information Figs. 2C and 2D). After 3 weeks, the number of SOX17 positive cells was markedly reduced and by 8 weeks none of the cells within the tumors expressed SOX17 (Fig. 3A). On the other hand, few SOX2 positive cells could be detected after 1 week, but the number increased steadily over time and after 8 weeks virtually all cells were positive for SOX2 (Supporting Infor- mation Figs. 2E and 2F; Fig. 2A). RT-PCR confirmed these findings and demonstrated that after 3 weeks the tumors already expressed robust amounts of $S O X 2$ and $C D 30$ while displaying variable amounts of SOX17 (Fig. 3A, 1-3, 4-6). These findings indicate that the transition to an EC-like tumor involves an initial and rapid induction of SOX2 within the first 3 weeks, while downregulation of SOX17 as well as a change in morphology takes 3-8 weeks.

To validate the EG-like nature of the tumors derived after injection of TCam-2 cells into the flank, we next compared them to tumors originating from the EC-line 2102EP after injection into the flank. Here, IHC analyses revealed that both tumors expressed comparable levels of SOX2 and CD30 and lacked expression of SOX17 (Fig. 3B). Furthermore, cytoplasmic location of BLIMP1 and 


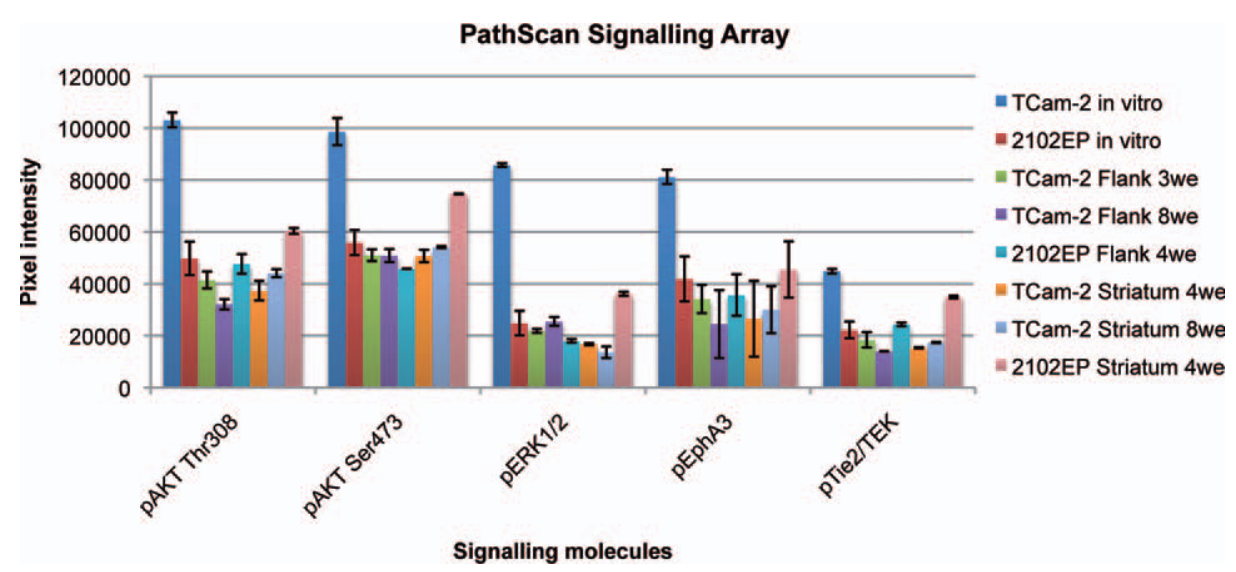

Figure 5. PathScan Signaling Array data of indicated signaling molecules of in vitro cultivated TCam-2 or 2I O2EP cells and TCam-2/2I02EP cells injected into the flank (Flank, after 3 and 8 weeks/4 weeks) or corpus striatum (Striatum, after 4 and 8 weeks/ 4 weeks). Standard deviation is indicated as error bars. [Color figure can be viewed in the online issue, which is available at wileyonlinelibrary.com.]

PRMT5 further underscored the EC-like nature of the tumors (Eckert et al., 2008a,b). Next, RT-PCR was performed to compare the expression of marker genes from the TCam-2 derived tumors in the flank to the parental TCam-2 line and 2102EP cells (Fig. 3C). TCam-2 derived tumors displayed upregulation of SOX2 and CD3O and downregulation of SOX17 to levels comparable to $2102 \mathrm{EP}$ controls (Fig. 3C). In addition, upregulation of $A F P$, $P A X 6$, and BRACHYURY (T) might indicate a beginning nonseminoma-like differentiation. The results suggest that the seminoma-like cell line TCam-2 is instructed by signals from the microenvironment to convert into a tumor resembling an EC after transplantation to the flank (Oosterhuis and Looijenga, 2005; Lind et al., 2007).

Since GCTs are also found in the CNS, we additionally transplanted TCam-2 and 2102EP cells into the corpus striatum of mice. One month after injection, tumors from TCam-2 cells displayed a typical EC-phenotype (Fig. 4A; HE) comparable to tumors generated by transplanting 2102EP cells. IHC staining and RT-PCR verified the EC-like character of the tumor cells (Fig. 4B; OCT3/4, SOX2, CD30 positive, and SOX17 negative). Similar to tumors derived from TCam-2 in the flank, a moderate upregulation of PAX6 and BRACHYURY (T) could be detected. Taken together these data indicate that TCam-2 cells, when injected into the corpus striatum, also adopt an EC-like character.

The tumor-microenvironment clearly instructed the fate of TCam-2 cells in vivo. We next aimed to elucidate signaling cascades altered during conversion of TCam-2 into an EC-like tumor. PathScan Signaling Arrays were performed and revealed that phosphorylation of AK'T (Thr308/ Ser743), ERK1/2 (Thr202/Tyr204), angiopoietin receptor Tie2/TEK (pan-Tyr), and ephrin TypeA receptor 3 (EphA3, pan-Tyr) was decreased in the EC-like tumors compared to the parental TCam-2 cells (Fig. 5, Supporting Information Fig. 3A). Interestingly, the phosphorylation levels of these signaling molecules in TCam-2 derived EC-like tumors were highly similar to the levels seen in 2102EP in vitro and in vivo control cells (Fig. 5, Supporting Information Fig. 3A). The reduced ERK1/2-phosphorylation (Thr202/ Tyr204) in vivo was verified by western blotting (Supporting Information Fig. 3B). In summary, these data indicate that the TCam-2 derived tumors not only express markers comparable to ECs, but also adopt an EC-like signaling signature in addition.

\section{DISCUSSION}

Here, we demonstrate that transplantation of the seminoma-like cell line TCam-2 into the seminiferous tubules results in CIS/seminomatous growth, while injection into the murine flank or brain leads to transition into and growth as an EC. Hence, we have established a versatile murine model system that allows analyzing human Type II GCTs and their progression from CIS in vivo.

Transplantation of TCam-2 cells into the testes resulted in growth of cells with a typical CIS-like morphology. Expression of markers indicative for CIS/seminoma and germ cells (NANOG, OCT3/4, SOX17, BLIMP1, TFAP2C, KIT) further demonstrated their CIS-like character (Jones et al., 2004; Oosterhuis and Looijenga, 2005). Additionally, 
cells with a different morphology could be detected after 3 months. Here, expression of PAX6 and AFP indicate differentiation into nonseminomatous GCT. These data demonstrate that TCam-2 cells grow as a CIS/seminoma in the seminiferous tubules for at least 3 months. Hence, our model recapitulates GCT development in vivo from intratubular CIS/seminoma to invasive growth and differentiation into nonseminoma. Further, the procedure of efferent duct transplantation is tolerated well by the mice (survival rate 28/30) and can be performed efficiently (up to 12 transplantations per day). In addition, the experiments can be monitored over 3 months, allowing for drug-response studies. In contrast to murine transgenic model systems, whose generations are time consuming, TCam-2 cells can be genetically modified quickly and easily in vitro before transplantation, allowing the fast in vivo analysis of a gene's role in GCT formation. After busulfan treatment (and TCam-2 transfer), regular spermatogenesis recovers and a functional testis microenvironment is provided until the tumor cells start invasion. Therefore, our animal model is highly comparable to human GC'T formation in vivo.

We demonstrated further that TCam-2 cells resemble an EC after injection into the murine flank or corpus striatum, indicated by the cellular morphology and downregulation of SOX17 as well as upregulation of SOX2 and CD30 (de Jong et al., 2008a,b). The rapid upregulation of SOX2 1 week after transplantation into the flank, which is neither accompanied by morphological changes nor downregulation of SOX17, might indicate that induction of SOX2 represents an early step in the transition of a CIS/seminoma into an EC. Furthermore, our data demonstrate that the transition process is accompanied by a decrease in AKT-, ERK1/2-, EphA3-, and Tie2/TEKphosphorylation.

FGFs and EGFs transduce their signals via the AKT- and ERK-signaling cascade (Kunath et al., 2007; Mayshar et al., 2008). In TCam-2 cells, $F G F 2$ seems to be the predominant inducer of AKT- and ERK-signaling, since FGF4 and EGF are expressed at low levels, as demonstrated by cDNA microarray analysis (Supporting Information Fig. 3C). Additionally, AKT1 and ERK2 seem to be the main downstream effectors of their corresponding pathways (Supporting Information Fig. 3C). In a previous study, we could show that FGF4- and EGF-supplementation induces TCam-2 cells to differentiate into a mixed nonseminoma. There, an EC-like interme- diate was not detected (Nettersheim et al., 2011). In this study, we see a reduction of AKT1- and ERK2-activation, which accompanies the transition from seminoma to an EC-like tumor. Therefore, reduction of both signaling pathways is an important event in this transition.

What are the mechanisms leading to reduction of FGFR- and EGFR-signaling? Angiopoietins, the ligands of Tie2/TEK, drive angiogenesis and tumor growth in a context-dependent manner (Ward and Dumont, 2002). Thereby, different angiopoietins act agonistic (Ang1, Ang4) or antagonistic (Ang2) in Tie2/TEK-activation (Ward and Dumont, 2002). Parental TCam-2 cells show high levels of Ang1 and low levels of the antagonist Ang2 expression (Supporting Information Fig. 3C), indicating active Tie2/TEK-signaling. In contrast, ECs and EC-like cells show decreased Tie2/TEKphosphorylation, which normally induces AKTand ERK1/2-signaling. Therefore, reduced Ang1/ Tie2/TEK-signaling might be responsible for diminished AKT- and ERK1/2-phosphorylation (Lee et al., 2004; Yuan et al., 2007). Of note, while our data demonstrate that EC-like tumor growth is accompanied by reduced Tie2/TEK-signaling, the biological effects of Ang/Tie2/TEK-signaling are strongly context dependent (Ward and Dumont, 2002). Hence, further studies are on the way to decipher the role of Ang/Tie2/TEK-signaling in CIS/seminomas and nonseminomas.

Ephrin (Eph)-receptors and their Ephrinligands are thought to be important regulators of aberrant cell-cell communication in tumor cells (Pasquale, 2010). Ephrin-As are the ligands to EphA-receptors (Pasquale, 2010) and Ephrins A1 and A5 are highly expressed in TCam-2 cells (Supporting Information Fig. 3C); hence they appear to be the main inducers of EphA3-signaling in these cells. The transition of TCam-2 cells to an EC-like state is accompanied by reduction of EphA3-signaling to levels detectable in the EC control cells. The reduction in EphA3-phosphorylation may be caused by downregulation of Ephrin-A1/A5. This observation may reflect a different dependence of seminomas and ECs to cell-cell communication and cell-stroma communication. This hypothesis is in line with the fact that seminomas, but not ECs, are strongly affected by anoikis in vivo (Olie et al., 1996).

In this study, we effectively established a versatile CIS/seminoma mouse model that allows recapitulating human GCT formation and progression from CIS in vivo. Additionally, we demonstrated a dependency of seminomatous 
differentiation processes to the microenvironment and highlighted SOX2-induction as well as inactivation of AKT-, ERK, Tie2/TEK-, and EphA3signaling as important regulators of these processes. Our study helps to obtain new insights into GC'T biology and the developmental connection between CIS, seminoma, and EC.

\section{ACKNOWLEDGMENTS}

We gratefully thank Ad Gillis, Leendert H. J. Looijenga and the Erasmus Center for Bioinformatics (University Medical Center, Rotterdam) for performing the Affymetrix-microarray experiment and helping us to analyze the dataset. We also thank Angela Egert, Susi Steiner, and Mathilde Hau-Liersch for technical assistance; Hans-Martin Jaeck and Giulio C. Spagnoli for providing the BLIMP1 and MAGE-A4 antibody, respectively.

\section{REFERENCES}

Adami HO, Bergstrom R, Mohner M, Zatonski W, Storm H, Ekbom A, Tretli S, Teppo L, Ziegler H, Rahu M, Gurevicius R., Stengrevics A. 1994. Testicular cancer in nine northern European countries. Int J Cancer 59:33-38.

Bronson DL, Andrews PW, Solter D, Cervenka J, Lange PH, Fraley EE. 1980. Cell line derived from a metastasis of a human testicular germ cell tumor. Cancer Res 40:2500-2506.

Damjanov I. 2004. From stem cells to germ cell tumors and back. Verh Dtsch Ges Pathol 88:39-44.

Damjanov I, Horvat B, Gibas Z. 1993. Retinoic acid-induced differentiation of the developmentally pluripotent human germ cell tumor-derived cell line, NCCIT. Lab Invest 68:220-232.

de Jong J, Stoop H, Gillis AJ, Hersmus R, van Gurp RJ, van de Geijn GJ, van Drunen E, Beverloo HB, Schneider DT, Sherlock JK, Baeten J, Kitazawa S, van Zoelen EJ, van Roozendaal K, Oosterhuis JW, Looijenga LH. 2008a. Further characterization of the first seminoma cell line TCam-2. Genes Chromosomes Cancer 47:185-196.

de Jong J, Stoop H, Gillis AJ, van Gurp RJ, van de Geijn GJ, Boer M, Hersmus R, Saunders PT, Anderson RA, Oosterhuis JW, Looijenga LH. 2008b. Differential expression of SOX17 and SOX2 in germ cells and stem cells has biological and clinical implications. J Pathol 215:21-30.

Eckert D, Biermann K, Nettersheim D, Gillis AJ, Steger K, Jack HM, Muller AM, Looijenga LH, Schorle H. 2008. Expression of BLIMP1/PRMT5 and concurrent histone $\mathrm{H} 2 \mathrm{~A} / \mathrm{H} 4$ arginine 3 dimethylation in fetal germ cells, CIS/IGCNU and germ cell tumors. BMC Dev Biol 8:106.

Eckert D, Nettersheim D, Heukamp LC, Kitazawa S, Biermann K, Schorle H. 2008. TCam-2 but not JKT-1 cells resemble seminoma in cell culture. Cell Tissue Res 331:529-538.
Hoei-Hansen CE, Rajpert-De Meyts E, Daugaard G, Skakkebaek NE. 2005. Carcinoma in situ testis, the progenitor of testicular germ cell tumors: A clinical review. Ann Oncol 16:863-868.

Jones TD, Ulbright TM, Eble JN, Cheng L. 2004. OCT4: A sensitive and specific biomarker for intratubular germ cell neoplasia of the testis. Clin Cancer Res 10:8544-8547.

Jorgensen N, Muller J, Giwercman A, Skakkebaek NE. 1990. Clinical and biological significance of carcinoma in situ of the testis. Cancer Surv 9:287-302.

Josephson R, Ording CJ, Liu Y, Shin S, Lakshmipathy U, Toumadje A, Love B, Chesnut JD, Andrews PW, Rao MS, Auerbach JM. 2007. Qualification of embryonal carcinoma 2102Ep as a reference for human embryonic stem cell research. Stem Cells 25:437-446.

Kunath T, Saba-El-Leil MK, Almousailleakh M, Wray J, Meloche S, Smith A. 2007. FGF stimulation of the Erk1/2 signaling cascade triggers transition of pluripotent embryonic stem cells from selfrenewal to lineage commitment. Development 134:2895-2902.

Lee HJ, Cho CH, Hwang SJ, Choi HH, Kim KT, Ahn SY, Kim JH, Oh JL, Lee GM, Koh GY. 2004. Biological characterization of angiopoietin-3 and angiopoietin-4. FASEB J 18:1200-1208.

Lind GE, Skotheim RI, Lothe RA. 2007. The epigenome of testicular germ cell tumors. Apmis 115:1147-1160.

Looijenga LH, Hersmus R, Gillis AJ, Pfundt R, Stoop HJ, van Gurp RJ, Veltman J, Summersgill B, Shipley J, McIntyre A, van der Spek P, Schoenmakers E, Oosterhuis JW. 2006. Genomic and expression profiling of human spermatocytic seminomas: primary spermatocyte as tumorigenic precursor and DMRT1 as candidate chromosome 9 Gene. Cancer Res 66:290-302.

Mayshar Y, Rom E, Chumakov I, Kronman A, Yayon A, Benvenisty N. 2008. Fibroblast growth factor 4 and its novel splice isoform have opposing effects on the maintenance of human embryonic stem cell self-renewal. Stem Cells 26:767-774.

Mizuno Y, Gotoh A, Kamidono S, Kitazawa S. 1993. Establishment and characterization of a new human testicular germ cell tumor cell line (TCam-2). Nippon Hinyokika Gakkai Zasshi 84:1211-1218.

Nettersheim D, Gillis AJ, Looijenga LH, Schorle H. 2011. TGFbeta1, EGF and FGF4 synergistically induce differentiation of the seminoma cell line TCam-2 into a cell type resembling mixed non-seminoma. Int J Androl 34:e189-203.

Olie RA, Boersma AW, Dekker MC, Nooter K, Looijenga LH, Oosterhuis JW. 1996. Apoptosis of human seminoma cells upon disruption of their microenvironment. Br J Cancer 73:10311036.

Oosterhuis JW, Looijenga LH. 2005. Testicular germ-cell tumors in a broader perspective. Nat Rev Cancer 5:210-222.

Pasquale EB. 2010. Eph receptors and ephrins in cancer: Bidirectional signaling and beyond. Nat Rev Cancer 10:165-180.

Sonne SB, Almstrup K, Dalgaard M, Juncker AS, Edsgard D, Ruban L, Harrison NJ, Schwager C, Abdollahi A, Huber PE, Brunak S, Gjerdrum LM, Moore HD, Andrews PW, Skakkebaek NE, Rajpert-De Meyts E, Leffers H. 2009. Analysis of gene expression profiles of microdissected cell populations indicates that testicular carcinoma in situ is an arrested gonocyte. Cancer Res 69:5241-5250.

Ward NL, Dumont DJ. 2002. The angiopoietins and Tie2/Tek: Adding to the complexity of cardiovascular development. Semin Cell Dev Biol 13:19-27.

Yuan HT, Venkatesha S, Chan B, Deutsch U, Mammoto T, Sukhatme VP, Woolf AS, Karumanchi SA 2007. Activation of the orphan endothelial receptor Tie1 modifies Tie2-mediated intracellular signaling and cell survival. FASEB J 21:3171-3183. 